\title{
\#EleNão e eleições brasileiras de 2018: a circulação de sentidos em grupos de mulheres no Facebook
}

\#EleNão and the 2018 Brasilian elections: the circulation of meanings in women's groups on Facebook

\#EleNão y elecciones brasileñas 2018: la circulación de sentidos en grupos de mujeres en Facebook

\author{
Diosana FRIGO \\ Universidade Federal de Santa Maria (UFSM) \\ diosanafrigo@gmail.com

\section{LUAn MORAES ROMERO} \\ Universidade Federal de Santa Maria (UFSM) \\ luan1648@gmail.com

\section{Viviane BORELLI} \\ Universidade Federal de Santa Maria (UFSM) \\ viviane.borelli@ufsm.br
}

Chasqui. Revista Latinoamericana de Comunicación

N. ${ }^{\circ}$ 148, diciembre 2021 - marzo 2022 (Sección Monográfico, pp. 89-106)

ISSN 1390-1079 / e-ISSN 1390-924X

Ecuador: CIESPAL

Recibido: 27-06-2021 / Aprobado: 12-11-2021 


\title{
Resumo
}

No contexto das eleições presidenciais de 2018, no Brasil, analisa-se a circulação de sentidos no grupo do Facebook "Mulheres unidas pela Democracia Santa Maria-RS”. Temos como conceito norteador a circulação de sentidos, que está situada nas discussões sobre o processo de midiatização da sociedade. Foram realizados dois movimentos metodológicos: inicialmente utilizamos o software Iramuteq com o intuito de recolhermos indícios para posteriormente serem feitas interpretações por meio da análise semiológica dos discursos (Verón, 2004). Dessa forma, a análise da circulação de sentidos teve tanto um olhar macro quanto micro. Por fim, fazemos inferências sobre as interações no grupo, o movimento \#EleNão e as eleições presidenciais brasileiras do ano de 2018.

Palavras-chave: midiatização, circulação, \#EleNão, plataformas digitais, Iramuteq.

\begin{abstract}
In the context of the 2018 presidential elections in Brazil, the circulation of meanings in the Facebook group "Women united for Democracy Santa Maria-RS" is analysed. Our guiding concept is the circulation of senses, which is situated in the discussions about the mediatization process of society. Two methodological movements were performed: initially we used the Iramuteq software in order to collect evidence for later interpretations to be made through semiological analysis of the speeches (Verón, 2004). Thus, the analysis of the circulation of meanings had both a look macro as well as micro. Finally, we make inferences about the interactions in the group, the \#EleNão movement and the Brazilian presidential elections of the year 2018.
\end{abstract}

Keywords: mediatization, circulation, \#EleNão, digital platforms, Iramuteq.

\section{Resumen}

En el contexto de las elecciones presidenciales de 2018, en Brasil, se analiza la circulación de sentidos en el grupo de Facebook "Mujeres unidas por la Democracia Santa Maria-RS”. Tenemos como concepto orientador la circulación de sentidos, que está situada en las discusiones sobre el proceso de midiatización de la sociedad. Se realizaron dos movimientos metodológicos: inicialmente utilizamos el software Iramuteq con el fin de recoger indicios para posteriormente ser hechas interpretaciones por medio del análisis semiológico de los discursos (Verón, 2004). De esta forma, el análisis de la circulación de sentidos tuvo tanto una mirada macro como micro. Por último, hacemos inferencias sobre las interacciones en el grupo, el movimiento \#EleNão y las elecciones presidenciales brasileñas del año 2018.

Palabras clave: midiatización, circulación, \#EleNão, plataformas digitales, Iramuteq. 


\section{Introdução}

Nas eleições presidenciais brasileiras de 2018, em contraposição à candidatura de Jair Messias Bolsonaro, milhões de mulheres insatisfeitas com a sua atuação ao longo de três décadas de carreira política e indignadas com seus discursos considerados machistas, misóginos, racistas e homofóbicos participaram de mobilizações sociais. Num primeiro momento, juntaram-se na plataforma digital (Van Dijck, Poell y De Waal, 2018) Facebook e, posteriormente, saíram às ruas em defesa dos seus direitos, atuando no movimento que ficou conhecido mundialmente como \#EleNão. Bolsonaro, até então do Partido Social Liberal (PSL) e atualmente do Partido Liberal (PL), é militar da reserva, cumpriu sete mandatos na Câmara dos Deputados e foi eleito presidente no segundo turno das eleições com 55,13\% dos votos contra 44,87\% de Fernando Haddad, do Partido dos Trabalhadores (PT). Desde a finalização deste artigo, com a eleição de Bolsonaro, seu governo envolveu-se em polêmicas sobre o manejo do meio ambiente, políticas públicas de apoio a mulheres, indígenas, pessoas em situação de vulnerabilidade social, além de ter sido questionado por diversos setores sobre a gestão da pandemia no Brasil.

Nos anos que antecederam a eleição, Bolsonaro adquiriu certa notoriedade com suas declarações conservadores e, muitas vezes, relacionadas à violência de gênero. Para citar alguns exemplos, em 2014, no plenário da Câmara dos Deputados, disse para a então colega deputada Maria do Rosário (PT), que não a "estupraria" porque ela "não merecia" (Falcão \& Guerreiro, 2014); em 2016, na sessão da Câmara que culminou com a decisão favorável ao impeachment da presidenta Dilma Rousseff(PT), ele homenageou Carlos Alberto Brilhante Ustra, "o pavor de Dilma Rousseff", torturador reconhecido pela Justiça e citado por Jair Bolsonaro por ter comandado violências contra Dilma durante a ditadura civil-militar brasileira (Barba y Wentzel, 2016); em 2017, em uma palestra no Clube Hebraica, no Rio de Janeiro, afirmou que a sua única filha mulher foi uma "fraquejada", já que os quatro mais velhos são homens (Fórum, 2017).

Com a proximidade das eleições de 2018, o cenário em que ocorriam diversas situações que remetem à polarização (Frigo, Dalmolin e Borelli, 2020 Braga, 2020) foi intensificado. Atitudes e comportamentos associados a fenômenos de polarização como “intolerância, incivilidade, antagonismo, má-fé argumentativa, fake news, hostilizações, discursos de ódio, proposições excludentes” (Braga 2020 , p. 20 , grifo do autor), tornaram-se ainda mais evidentes no processo eleitoral. Nesse contexto, no dia 30 de agosto de 2018 foi criado, no Facebook, o grupo "Mulheres Unidas Contra Bolsonaro" (MUCB). Formado apenas por mulheres, o grupo expandiu-se rapidamente - com duas semanas de existência atingiu a marca de um milhão de integrantes e com menos de um mês eram mais de três milhões - demonstrando o quanto muitas mulheres sentiam-se subjugadas na campanha do então candidato à presidente e a preocupação delas 
em relação ao cenário brasileiro com a possível eleição de Bolsonaro, líder nas pesquisas eleitorais.

As membras do MUCB buscavam formas de protestar e também de modificar o rumo que se delineava, tanto a partir de ações online como fora desse espaço. Em meio às reflexões sobre como se organizar coletivamente e às trocas de informações no grupo, foi chamado um ato em São Paulo (SP), para o dia 29 de setembro de 2018. Essa ação suscitou a criação de grupos no Facebook em vários locais do Brasil, em que as mulheres passaram a organizar atos unificados nacionalmente em suas cidades. Também ocorreram atos internacionais em capitais como Tóquio, Paris, Buenos Aires, Lisboa e Nova York.

Em Santa Maria, localizada na região central do Rio Grande do Sul, no extremo sul do país, o movimento \#EleNão teve como expoente o grupo local no Facebook. O grupo foi criado em 11 de setembro de 2018, com o nome de "Mulheres unidas SM/RS ELENÃO". No dia 8 de outubro de 2018, um dia após o primeiro turno das eleições presidenciais - que teve Jair Bolsonaro em primeiro lugar (46\%) e Fernando Haddad em segundo (29\%) para a disputa no segundo turno-, o grupo tornou-se "Mulheres unidas pela Democracia Santa Maria-RS".

A partir desse contexto, o objetivo do artigo é analisar a circulação de sentidos no grupo "Mulheres unidas pela Democracia Santa Maria-RS”, no período de outubro de 2018 , tendo em vista que esse eixo temporal abrange o primeiro (8 de outubro de 2018) e o segundo turno (28 de outubro de 2018) das eleições presidenciais. A reflexão acerca da circulação de sentidos nesses grupos faz parte de pesquisa em desenvolvimento (Frigo, 2018). Para isso, temos como conceito norteador a circulação, conforme propõem Braga $(2012,2017)$ e Fausto Neto (2018), situado nas discussões sobre o processo de midiatização da sociedade, a partir de Verón (1997) e novamente Fausto Neto (2018). Do ponto de vista metodológico, a investigação baseia-se em dois movimentos: no primeiro, com o intuito de recolhermos indícios para a pesquisa, utilizamos o software Iramuteq; ' já o segundo movimento, diz respeito à análise semiológica dos discursos (Verón, 2004), que nos auxilia na análise da circulação de sentidos sobre o \#EleNão.

\section{A construção teórico-metodológica}

O conceito de midiatização é compreendido como um processo em curso e que está em andamento. Assim, com a complexificação da sociedade e a dinamização dos processos midiáticos ao longo das últimas décadas, pode-se afirmar que as transformações "estariam a indicar o rastro de complexas interfaces entre práticas sociais a partir de um outro tipo de mediação engendrada por lógicas dos processos midiáticos" (Fausto Neto, 2018, p. 76). Cabe dizer que em 1997, Eliseo Verón já afirmava que as afetações emergentes das relações entre atores

1 Interface de R pour les Analyses Multidimensionnelles de Textes et de Questionnaires. 
sociais, instituições e mídias, mostravam que a última ocupa um papel central na organização social na medida que se torna indissociável da estrutura da sociedade. Para o autor, formam-se coletivos que se afetam mutuamente nas processualidades da midiatização.

No esquema para análise da midiatização, Verón (1997, p. 15) aponta que nas complexas relações entre os atores individuais, instituições e mídias existem quatro zonas de produção de coletivos. A primeira é a relação das mídias com as instituições; a segunda é a relação das mídias com os atores individuais; já a terceira diz respeito à relação das instituições com os atores; e a última zona refere-se à forma como as mídias afetam a relação entre as instituições e os atores individuais. Desse modo, Fausto Neto (2018) afirma que há complexas interpenetrações advindas da produção de sentidos dos sistemas institucionais (midiático) e dos atores sociais.

Destacamos também que na sociedade em midiatização os processos comunicacionais ocorrem de modo difuso e não linear, entendendo que todos os interagentes podem participar tanto na produção como no reconhecimento (Verón, 2004), acarretando a circulação discursiva em caminhos diversos. Dito isso, Braga (2012) afirma que a circulação de sentidos ocorre em fluxos sempre adiante e contínuos diante das complexidades que perpassam as interações entre os participantes. Além do mais, segundo Braga (2017), a circulação funciona por meio de apropriações de sentidos e há um constante embate ou negociação entre os participantes na processualidade comunicacional para que os fluxos sigam adiante. No caso do grupo estudado, entendemos que todas as participantes são igualmente produtoras de discursos (seja ao realizar uma postagem ou comentário) e, portanto, deixam rastros que podem ser analisados, como lembra Verón (2004), a partir da matéria significante que o analista tem em mãos.

Em relação aos procedimentos metodológicos, realizamos a coleta dos observáveis no grupo "Mulheres unidas pela Democracia Santa Maria-RS" a partir do mecanismo de busca na plataforma digital, em que é possível delimitar mês, ano e palavra-chave, por exemplo. A palavra-chave eleita foi “\#elenão”, por compreendermos que a partir desse termo não restringimos a pesquisa ao processo eleitoral apenas, pois possibilita olhares direcionados para o movimento de mulheres, de maneira geral. O eixo temporal, por sua vez, é composto pelo mês de outubro de 2018, período que abrange as eleições. Além disso, de acordo com as opções permitidas por esse mecanismo da plataforma, a coleta ocorreu entre todas as publicações (tipo de publicação), as mais relevantes (classificação), as realizadas por qualquer pessoa do grupo (publicado por) e as publicadas de qualquer lugar (localização marcada).

Com base nesses procedimentos, coletamos 90 postagens textuais, excluindo-se postagem em que não existiam dados textuais. Então, os textos foram copiados e colados em um documento no Word. A partir disso, ocorreu o tratamento dos dados para que pudessem ser inseridos no software de análise 
lexicométrica Iramuteq; depois, geramos as tabelas da análise estatística, a nuvem de palavras e os gráficos de árvore máxima da análise de similitude (Degenne y Vergès, 1973).

Com relação à primeira análise, o software faz de maneira automatizada a lematização das palavras (Lebart, Salem y Berry, 1998), classificando cada uma de acordo com a sua classe morfológica. Para esta investigação, optamos por deixar em evidência, como formas ativas, os adjetivos, os substantivos, os verbos e as formas não reconhecidas pelo software. Tal análise dá subsídios para calcular a frequência dos vocábulos encontrados nos textos das postagens, assim como através das tabelas geradas por ela podemos voltar aos textos originais e criar subcorpus para análise.

Dito isso, geramos uma nuvem de palavras, em que aparecem de maneira gráfica os vocábulos que possuem maior frequência de aparecimento nos textos das postagens. Assim, é possível inferir quais são as que emergem com maior centralidade na nuvem, ou seja, quais são usadas com maior recorrência nas postagens. Já com relação ao gráfico de árvore máxima da análise de similitude, fizemos uma exportação e usamos o software Gephi para gerar uma melhor visualização. É nesse transporte que se evidencia a métrica da centralidade de intermediação (Newman y Girvan, 2004; Brandes, 2001), na qual compreendemos como as palavras articulam-se umas com as outras, além de termos noção da importância local de cada uma delas. ${ }^{2}$

Com relação aos achados, partimos de um corpus de investigação com 90 segmentos de texto, tendo 8.154 ocorrências de vocábulos, com 944 aparecendo uma única vez. Com a opção metodológica de analisar certas classes morfológicas, temos $43,23 \%$ de palavras ativas e $8,40 \%$ de palavras suplementares. Na primeira abordagem analítica, em que observamos as tabelas de frequência geradas e também a nuvem de palavras, notamos que os seguintes vocábulos emergem com alta frequência relativa ao total de ocorrências nos enunciados: "elenão" (1,214\%); "bolsonaro" (o,540\%); "votar" (o,540\%); "voto" (o,527\%); "haddad" (o,478\%); "turno" (0,442\%); "candidato" (0,405\%); "mulher" (o,392\%); "só" (o,392\%); "pt" (o,368\%). A árvore máxima a partir do corpus em investigação pode ser vista na Figura 1.

2 Romero (2021) propôs essa analítica como uma forma de investigar a circulação de sentidos no caso das três primeiras reportagens da série "Vaza Jato" publicadas pelo The Intercept Brasil no site da Agência, no Youtube e na Fanpage. 
Figura 1. Árvore máxima

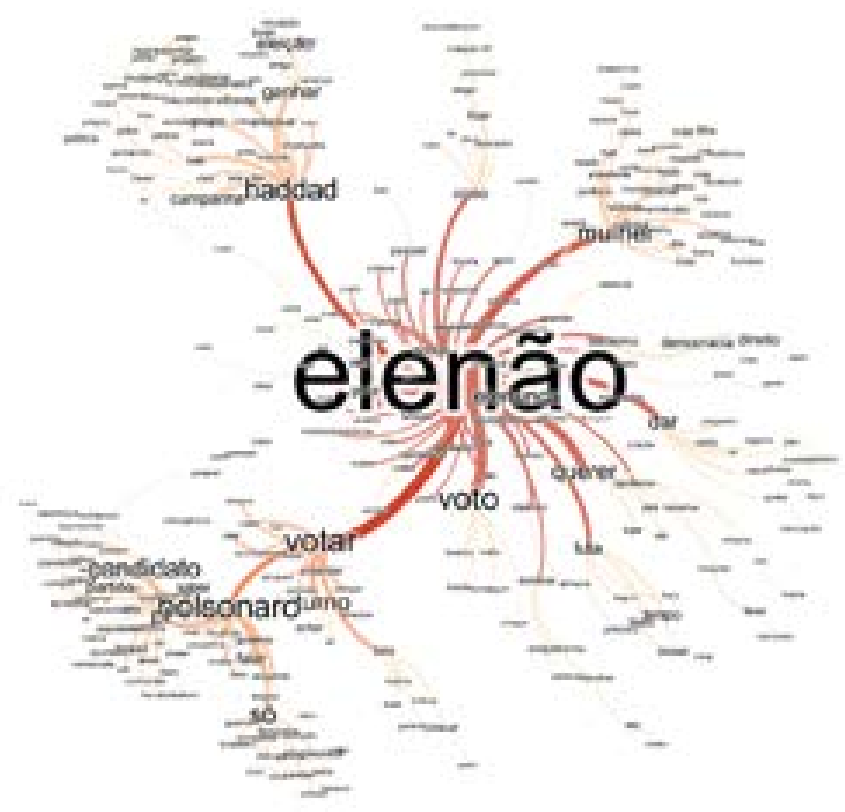

Elaboração própria

Além disso, na árvore máxima produzida emergem grupos de palavras que possuem relação com os principais candidatos a presidente nas eleições de 2018, tendo uma predominância em ordem decrescente de menções a Jair Bolsonaro ("bolsonaro" possui 19.034 de CI), Fernando Haddad ("haddad" possui 14.252 de CI) e Ciro Gomes ("ciro" possui 1.832 de CI). Ademais, uma comunidade de vocábulos que surge com expressividade tanto em termos de frequência relativa quanto em centralidade de intermediação tem conexão direta com a hashtag “\#EleNão" ("EleNão" possui 40.645 de CI) e a palavra "mulher" ("mulher" possui 11.159 de CI).

Assim, para compor um corpus de análise, voltamos para as postagens que se relacionam com a menção à palavra "mulher" para podermos analisar os comentários. Tal opção é feita para compreender de forma aprofundada ${ }^{3}$ como ocorre a circulação discursiva das temáticas envolvidas com esse vocábulo. Nessa perspectiva, constitui-se um subcorpus que conta com 17 textos provenientes da análise anterior e, a partir de uma primeira observação realizada nessas postagens, coletamos 142 comentários.

3 Romero (2021) também articula os dados quantitativos gerados por softwares e os textos para analisar a circulação de sentidos. 
Assim, partimos de 17 postagens e 142 comentários e com base na análise semiológica dos discursos, perspectiva trabalhada por Eliseo Verón, são feitas inferências a respeito dos sentidos em circulação no processo eleitoral e no movimento \#EleNão. Para Verón (2004, p. 61), o discurso é “qualquer conjunto significante considerado como tal (isto é, considerado como lugar de investimento de sentido)" e desenha não um único efeito, mas sim um "campo de efeitos de sentido" (Verón, 2004, p. 216, grifo do autor).

\section{Circulação de sentidos no "Mulheres unidas pela Democracia Santa Maria-RS"}

O grupo no Facebook é privado e oculto, ou seja, somente quem está no grupo pode ver as publicações bem como encontrá-lo na plataforma. No entanto, após a divulgação do resultado das eleições e com Bolsonaro eleito, o grupo permaneceu por algum tempo como secreto "por questões de segurança", segundo escreveu uma das administradoras em um aviso publicado no dia 28 de outubro de 2018. Há quatro administradoras e um total de 7.700 integrantes. ${ }^{4}$ Apesar das postagens não necessitarem de autorização, isto é, qualquer pessoa no grupo pode realizá-las bem como fazer comentários, o grupo não possui atividade constante, pois a última postagem foi no dia 27 de março de 2020 . Ou seja, a temporalidade é um fator central em que o período eleitoral constituiu-se em seu ápice.

Assim, partindo de um olhar mais macro sobre a matéria significante coletada inicialmente, conseguimos identificar marcas discursivas que nos possibilitaram reunir as enunciações em três grandes agrupamentos de sentidos, são eles: "votar contra Bolsonaro", "posicionamento político" e "pedido de ajuda". A seguir, tem-se um olhar mais micro para os discursos produzidos no grupo e, para tal, elegemos alguns fragmentos discursivos. A escolha dessa matéria significante para análise mais detalhada foi feita a partir de recorrências, em que foram identificadas marcas discursivas que se repetiam ao longo das postagens e comentários.

Para sistematizar a análise, os enunciados foram numerados em ordem crescente e apresentados como "E”, por exemplo: E1, E2, E3 e assim sucessivamente. Além do mais, traços discursivos foram destacados em negrito, preservando-se a identidade das participantes e retirando marcas de identificação.

\subsection{Votar contra Bolsonaro}

Muitos sentidos que emergiram na circulação no grupo estavam relacionados à obrigação das mulheres votarem contra Bolsonaro. Não eram vistos horizontes positivos em relação às políticas públicas perspectivando o sexo feminino,

4 Retirado de https://www.facebook.com/groups/2376837692334284/about. Acesso em 7 maio 2021. 
pelo contrário, as mulheres presentes no grupo do Facebook evocavam a obrigatoriedade de não votarem em Bolsonaro justamente por entenderem que já estavam sendo desrespeitadas inclusive durante a campanha eleitoral.

[...] Nossa OBRIGAÇÃo enquanto mulheres, mães, filhas, esposas, trabalhadoras, estudantes, MULHERES BRASILEIRAS, é apertar o 13 e derrubar o Bolsonaro.

TEMOS QUE NOS UNIR! SÓ TEMOS UMA OPÇÃO E TEMOS QUE SER FIRMES COM ELA.

Votar nulo ou em branco é dar as costas ao movimento \#EleNão. [...] (E1)

O momento é muito sério, falamos em violência, desrespeito, injustiças! TODAS

CONTRA ELE!!!! Agora é \#Haddadsim gurias! (E2)

No primeiro enunciado (E1), a demarcação da obrigatoriedade das mulheres votar contra Bolsonaro - e consequentemente em Fernando Haddad no segundo turno das eleições presidenciais - é evidente quando o enunciador interpela as "mulheres, mães, filhas, esposas, trabalhadoras, estudantes, mulheres brasileiras" para votar no número 13 (Haddad). Além disso, a caixa alta na escrita de "mulheres brasileiras" e "obrigação" é uma marca para chamar a atenção e destacar a ordem ali presente: ser mulher e votar em Bolsonaro é incoerente, por isso todas devem votar contra. Ainda nesse enunciado, sublinhamos a relação direta feita com o movimento \#EleNão, quando é evocado que voto "nulo ou em branco é dar as costas ao movimento".

Já em E2, há preocupação com aquele momento particular que o país vivenciava - “de violência, desrespeito, injustiças" - e, portanto, o enunciador retoma os sentidos de ordem proferindo que todas devem votar contra Bolsonaro. Além da ênfase dada ao discurso escrito em caixa alta, como também observado anteriormente, há o uso de pontos de exclamação.

A convocatória, além da ordem, é um outro sentido posto em circulação no grupo. São enunciados que convocam não só as mulheres a votar contra Bolsonaro, mas como elas devem ir no dia da votação manifestando-se "sem nada falar". Como em E1, E3 também faz referência direta ao movimento \#EleNão.

Recebi esse recado da minha autora preferida, Maria Valéria Rezende pelo mnsg do face e me comprometi passar adiante:

"Nós mulheres vamos vestidas de branco votar. $E$ todas nós vestidas de branco estaremos dizendo sem nada falar: ELE NÃO! Desejamos PAZ!

Vamos iniciar essa corrente agora para o máximo de mulheres! Ainda dá tempo!!"

\#eleNão (E3)

É interessante destacar que, nesse enunciado, a convocatória para que as mulheres vistam-se de branco no dia da votação (simbolizando a paz e também 
a adesão ao \#EleNão) é um fragmento já circulado anteriormente em algum outro espaço (não citado), pois refere-se a um "recado" recebido e passado adiante. A lógica das "correntes" na ambiência da midiatização ilustra o fluxo comunicacional que "acontece em variadíssimas formas - desde a reposição do próprio produto para outros usuários (modificado ou não); à elaboração de comentários - que podem resultar em textos publicados ou em simples 'conversas de bar', por exemplo" (Braga, 2017, p. 52). A participante pretende que o produto continue circulando quando diz "vamos iniciar essa corrente agora para o máximo de mulheres".

Outros sentidos em circulação no grupo dizem respeito a relatos sobre familiares que iriam votar em Bolsonaro ao mesmo tempo que outras mencionavam o apoio e a solidariedade da família com elas. A seguir, podemos visualizar os enunciados E4, E5 e E6, nos quais há disputas de sentidos e a intenção de que os fluxos sigam adiante (Braga, 2012, 2017).

Feliz porque minha família inteira, homens e mulheres, votam \#elenao, não votam nele 11 votos a menos nele... (E4)

Minha família de origem é enorme, 80 \% vai de Haddad. A família que constituí é 100\% Haddad. (E5)

Queria a mesma alegria... Mas da minha familia so eu meu marido e mais uns 3 que \#elenao (E6)

Nos enunciados E4 e E5, os relatos correspondem às famílias que não votariam em Bolsonaro. Já em E6, a participante da interação responde a um discurso anterior afirmando que "queria a mesma alegria" da família não votar em Bolsonaro. Outro destaque a ser feito em relação ao E4, e E6, é a utilização da nomenclatura \#EleNão, para dizer que não votam em Bolsonaro ("votam elenão"). Dessa forma, as participantes ativam a expressão ressignificando-a com novas apropriações de sentidos que são reconstruídos e repostos para circular em outros fluxos discursivos.

No grupo, também há enunciados que agradecem a quem aderiu ao movimento \#EleNão. A seguir, podemos visualizar um exemplo.

Gurias,

Eu gostaria de dar os parabéns e agradecer por cada uma de vocês, que aderiu ao \#ELENÃO e que neste momento estão nos apoiando agora no $2^{\circ}$ turno. [...]

Agradeço a cada uma de vocês que está conosco militantes do PT mesmo sendo contra o partido, sendo de outro partido, de partidos coligados,anti pt e de outros partidos e afins.

Isso me mostra o quanto a união é importante no momento mais frágil e importante em que nossa DEMOCRACIA está em jogo.

Avante, até a vitória.

Vamos somar e juntas comemorar... Gratidão! (E7) 
Em E7, a participante agradece "por cada uma de vocês, que aderiu ao \#ELENÃO e que neste momento estão nos apoiando agora no $2^{\circ}$ turno" e segue "agradeço a cada uma de vocês que está conosco militantes do PT". Neste caso, a participante refere-se como integrante do movimento \#EleNão, no entanto, ao agradecer a não eleição de Jair Messias Bolsonaro assim como o apoio no $2^{\circ}$ turno, não deixa explícito se "estão nos apoiando" está relacionado ao PT ou ao movimento \#EleNão.

Foram construídos discursos que remetem a desabafos sobre possíveis retiradas de direitos das mulheres caso efetivada a eleição de Bolsonaro para presidente do país e o que isso representaria historicamente. Em E8, a enunciação de uma mulher de mais de 50 anos ressalta no seu dito o papel que era delegado a elas décadas atrás e como isso havia sido modificado ao longo dos anos. Ela conclui que os direitos conquistados não poderiam ser retrocedidos.

Eu estou ansiosa, simm...

Mas, a unica coisa que eu tenho certeza é que amanhã é \#ELENÃO \#ELENUNCA \#ELEJAMAIS...

Nestes meus 50 anos eu vi muitas conquistas das mulheres e isso não pode ser ameaçado...Nós eramos ensinadas a obedecer os pais e depois os maridos,nossa função era ter filhos(nada contra) e cuidar da casa... [...] (E8)

Bem isso! Agora que minha mãe encontrou a voz dela, não vou permitir que a calem, que nos calem! \#EleNao (E9)

Em E9, temos mais um fluxo comunicacional quando outra participante responde ao E8. Isso demonstra, mais uma vez, o que Braga $(2012,2017)$ compreende por fluxos adiante na circulação. Em E8, assim como na enunciação seguinte, também está evidente a relação com o movimento \#EleNão, por exemplo, quando a participante afirma que "amanhã é \#EleNão", fazendo menção ao dia da votação.

Foram identificados ainda enunciados que são apelos tanto para os homens (E10) como para as mulheres de direita (E11) para que não votassem em Bolsonaro.

Apelo aos homens

Apelo de uma mãe, de uma avó, de uma filha, de uma irmã, de uma sobrinha, de uma neta, de uma sobrinha, de uma prima, de uma namorada, de uma companheira, de uma mulher... (E10)

Mulheres de direita, meu apelo é pra vocês, pois quando alguém de esquerda argumenta contra o a pessoa não escuta ou acha que nossa repulsa por ele é mais um motivo pra apoiar. Vocês têm mais alcance pra argumentar e indicar outro candidato. (E11) 
De forma bastante explícita ("apelo de uma mãe, de uma avó"; "mulheres de direita, meu apelo é pra vocês”), as participantes evocam discursos apelativos para que as mulheres de direita, mesmo discordando sobre qual candidato votar, não votem especificamente em Bolsonaro. Ao mesmo tempo, há enunciados que fazem um apelo aos homens, no entanto, não há homens no grupo — pois é exclusivo para mulheres - , o que nos faz inferir que é mais um produto advindo das complexas lógicas de produção, circulação e reconhecimento de discursos. Neste caso, pode ter sido um enunciado já postado em outra plataforma e que foi colocado também no grupo do Facebook.

\subsection{Posicionamento político}

O conjunto de enunciados a seguir, além de ilustrar o fluxo adiante na circulação elaborado por Braga $(2012,2017)$, também exemplifica parte da disputa de sentidos presente no grupo em relação às nomenclaturas que as mulheres deveriam utilizar para manifestarem-se no segundo turno das eleições. Isso evidencia que os coletivos, mesmo sendo constituídos por afinidades e interesses comuns, também possuem tensionamentos e visões diferentes sobre determinados assuntos.

\section{Mensagem encaminhada pelo WhatsApp}

Neurolguisticamente falando...

Sim.

É preciso que as mulheres modifiquem sua bandeira de luta para o modo afirmativo ou seja: \#HaddadSIM.

Isso é uma lei da comunicação. Se permanecer o \#elenão quem fica no foco é o coiso.

Portanto, quem estiver ligada às mulheres e à luta feminista conversa com a galera e muda já para \#HaddadSIM beijo e sigamos rumo a conquista de um brasil com mais solidariedade social soberania respeito às diferenças educação e saúde pública e de qualidade. (E12)

O E12 circulou em outras plataformas digitais, confirmando as proposições de Braga (2012, 2017) ao explanar sobre os fluxos adiante e contínuos na processualidade comunicacional. Essas interpenetrações ocorrem devido à produção de sentidos promovida pelos sistemas midiáticos e atores sociais conforme defendido por Fausto Neto (2018), permitindo que a circulação discursiva percorra caminhos diversos e não previstos, como destaca Verón (2004).

Ainda, a circulação ocorre a partir de apropriações de sentidos, os quais estão constantemente em disputa na sociedade (Braga, 2012, 2017). Esse embate, pode ser percebido na processualidade comunicacional, como em E12, no qual são visíveis as disputadas sobre como deveria ocorrer às manifestações 
das mulheres em relação ao segundo turno: se a nomenclatura defendida permaneceria \#EleNão ou seria modificada para \#HaddadSim.

Em relação aos fragmentos discursivos em que os enunciados correspondem a sentidos postos em circulação sobre fake news, notamos que, assim como no agrupamento anterior, esse também evidencia interpenetrações e tensionamentos complexos (Fausto Neto, 2018) no momento que, por exemplo, em E14, a participante compartilha um link da plataforma Twitter - local em que estaria especificado métodos de contra-ataque às fake news. Ainda em E14, a participante sugere para as outras interagentes que leiam o material compartilhado, mantendo os fluxos em circulação.

Para esse segundo turno acredito que devemos focar nossos esforços em combater as fakenews e promover o plano de governo de Fernando Haddad. $\mathrm{O}$ que acham de começarmos pelas políticas públicas voltadas para nós mulheres? [...] (E13)

acho que combater fake news a essa altura do campeonato é desperdício de energia. Sugiro que todas que possam, leiam essa thread. Tem métodos de contra ataque.

https://twitter.com/AZzacchi/status/1047817320322805762?s=19 (E14)

Precisamos demonstrar que as fakenews estão sendo utilizadas pelo candidato da barbárie, pois a mamadeira erótica é falta de caráter... (E15)

Outra observação pertinente, diz respeito à disputa de sentidos em relação ao foco no segundo turno estar centrado ou não no combate às fake news. Em E14, a participante discorda que fake news seja importante no momento. Diferentemente das participantes em E13 e E15, que defendem ser oportuno demandar esforços para evidenciar que as fake news estavam sendo utilizadas contra o candidato Fernando Haddad, desinformando eleitores em potencial. Em E15, a participante ainda afirma que "fakenews estão sendo utilizadas pelo candidato da barbárie", referindo-se a Bolsonaro como "candidato da barbárie".

A partir destes enunciados sobre fake news fica perceptível uma situação de polarização (Braga, 2020) no contexto político eleitoral do ano de 2018 e que segue em 2021. Nas últimas eleições, perfis falsos e robôs foram utilizados favorecendo a circulação de fake news, que são disseminadas em especial por grupos de WhatsApp, como ocorreu nos Estados Unidos da América (EUA) e no Brasil, respectivamente em apoio ao Donald Trump e ao Jair Bolsonaro (Frigo, Dalmolin e Borelli, 2020). Comportamentos e atitudes que podem ser associados a fenômenos de polarização, como as fake news, "são ao mesmo tempo sintomas e reiteração do processo" (Braga, 2020, p. 20). Além do mais, as observações empíricas em circuitos comunicacionais e que coincidem com a circulação informativa de atualidades, reforçam "a midiatização como arena em que podemos acompanhar grande parte dos embates” (Braga, 2020, p. 21). 
Identificamos traços acerca das teorizações de Braga $(2012,2017)$ sobre a circulação em fluxos adiante no processo comunicacional em discursos sobre o papel da "mulher Manuela" durante a campanha eleitoral. Manuela d'Ávila, do Partido Comunista do Brasil (PCdoB), concorreu ao cargo de vice-presidenta com Fernando Haddad.

O que me incomoda horrores é que Fernando Haddad não respeita Manuela! Vcs viram o pronunciamento? Ela estava ao lado dele e ele agradeceu a coligação e nem citou o nome... Foi o público que gritou o nome de Manuela, assim como em outros momentos que ela fica de lado, não fala nunca da sua vice nos debates, quase não aparece nas divulgações! Eu fui na página deles ejá escrevi sobre isso. Se eles não valorizarem ela e não deixarem ela falar Haddad não irá ganhar. [...] (E16)

A participante traz para a interação no grupo do Facebook um produto (pronunciamento realizado em outra materialidade), a partir de apropriações de sentidos, que também segue adiante quando ela diz "fui na página deles e já escrevi sobre isso". Conforme Braga (2017), o produto que está circulando segue sempre adiante devido aos sentidos apropriados pelos participantes em cada interação, desse modo, não é, necessariamente, o objeto inicial de um percurso, mas o momento de um circuito que já começou e não terminou.

\subsection{Pedido de ajuda}

O último conjunto de enunciados eleitos para análise está centrado em pedidos de ajuda, seja com caronas para votar (E17), vestimenta para o dia da votação (E18) ou pesquisas online relacionadas ao movimento \#EleNão (E19).

Alguma mulher saindo de SM -> POA no sábado para votar \#elenão? estou buscando uma carona, ajudo nos custos (E17)

Ha alguns dias vi um post de uma mulher perguntando se poderia ir com a camiseta do \#EleNão ta aí, pode! (E18)

Mulheres está rolando essa pesquisa aqui, bora votar!!

\#EleNão (E19)

As mulheres se manifestaram no grupo também de forma solidária umas com as outras, já que, conforme visto em E18, a participante responde uma postagem que viu "há alguns dias" de alguém perguntando se poderia ir voltar “com a camiseta do EleNão". Os sentidos são construídos e reorganizados para seguirem em processos não lineares e caminhos não previstos (Verón, 2004). 


\section{Considerações}

Com o objetivo de analisar a circulação de sentidos no grupo do Facebook "Mulheres unidas pela Democracia Santa Maria-RS", no contexto das eleições presidenciais de 2018, recolhemos inicialmente materiais correspondentes ao mês de outubro de 2018 (que compreende tanto o primeiro como o segundo turno eleitoral). Posteriormente, observamos possibilidades de utilização do software Iramuteq, tendo em vista a demanda manual e humana por vezes inviável de ser realizada. No entanto, ressaltamos a importância de trabalhar com o software concomitantemente com abordagens qualitativas, além de ser necessário ter visão crítica em relação aos dados apresentados. Para isso, baseamo-nos na análise semiológica dos discursos (Verón, 2004), por compreender que seria necessário identificar traços nos fragmentos discursivos postos em circulação tanto de modo micro quanto macro, permitindo a realização de algumas inferências sobre as interações no grupo, o movimento \#EleNão e o contexto eleitoral.

Assim sendo, a partir dos indícios identificados por meio de análise quantitativa possibilitada pelo Iramuteq e de movimentos observacionais, os enunciados foram divididos em três grandes agrupamentos: "votar contra Bolsonaro", "posicionamento político" e "pedido de ajuda". Como cada grupo possui suas singularidades, são feitas algumas inferências a seguir.

No primeiro grande agrupamento, "votar contra Bolsonaro", os discursos ressaltam a obrigação das mulheres votarem contra Bolsonaro,já que seriam uma das partes da sociedade mais prejudicada com o seu governo. Além disso, há uma relação direta feita com o movimento \#EleNão quando é evocado que voto "nulo ou em branco é dar as costas ao movimento". No agrupamento de convocatória também é feita menção ao \#EleNão quando as participantes convocam as mulheres a irem vestidas de branco no dia da votação (forma simbólica de mostrar que não votariam em Bolsonaro). Também identificamos enunciados com relatos das participantes sobre familiares que iriam votar em Bolsonaro ou não, nos quais destacamos disputas de sentidos (Fausto Neto, 2018; Verón, 2004) em relação aos relatos bem como fluxos adiante na circulação (Braga, 2012, 2017). Cabe citar que as participantes demonstram gratidão às mulheres que aderiram ao movimento \#EleNão durante as eleições e demonstram preocupação em relação às possíveis retiradas de direitos das mulheres caso efetivada a eleição de Bolsonaro, por meio de interações complexas quando respondem umas às outras. Ainda, há enunciados que fazem um apelo aos homens, mesmo que eles não integrem o grupo, o que nos faz inferir que é mais um produto advindo das complexas lógicas de produção e circulação de sentidos.

O segundo grande agrupamento, "posicionamento político", ilustra fluxos complexos na circulação, em que discursos vindos de outras plataformas (Van Dijck, Poell y De Waal, 2018), remetem a disputas de sentidos no grupo em relação às nomenclaturas que as mulheres deveriam utilizar para manifestarem-se no 
segundo turno das eleições. Nos enunciados sobre fake news, há embates em relação ao foco no segundo turno estar centrado ou não no combate às fake news; há situação de polarização no contexto político eleitoral de 2018 e que segue em 2021; além do compartilhamento de links de outra plataforma, como o Twitter, em que a participante sugere que as interagentes leiam o material compartilhado e assim possam alimentar os fluxos em constante circulação.

No último grande agrupamento, "pedido de ajuda”, é possível verificar que os sentidos são construídos e reorganizados para seguirem adiante. Entre pedidos de ajuda para caronas, o que vestir no dia da votação e pesquisas online sobre o \#EleNão, percebemos que mesmo transcorrido o tempo que uma pergunta foi feita, as participantes respondem umas às outras (mantendo a interação) com o intuito de ainda tentar ajudar. Isso remete também ao modo empático e solidário com que as participantes relacionam-se.

Embora não tenha somado forças suficientes para cumprir seu objetivo constituinte - derrotar Bolsonaro nas urnas-, o \#EleNão mantém-se ativo no grupo nacional. O MUCB, desde a fundação, reitera a necessidade de unidade, fortalecimento e afirmação das mulheres como seres políticos e detentoras de direitos, especialmente em um contexto como o das eleições de 2018, que evidenciou situações de polarização (Braga, 2020), com a ascensão de movimentos de direita.

Importante também fazer menção a alguns exemplos sobre o contexto brasileiro para as mulheres após Bolsonaro ser eleito. Ao completar dois anos de governo, em 2020, o presidente foi denunciado na Organização das Nações Unidas (ONU) por 54 casos de ataques contra mulheres jornalistas (FENAJ, 2020); o Ministério Público Federal (MPF) apresentou ação civil pública contra o governo por posturas e declarações discriminatórias sobre as mulheres (ISTOÉ, 2020); em meio à pandemia do Coronavírus, o presidente vetou o projeto de lei que previa a prioridade a mulher chefe de família no pagamento do auxílio emergencial (G1, 2020); e em 2020, a ONU Mulheres Brasil afirmou que o país estava com um dos piores indicadores da América Latina no que diz respeito aos direitos políticos das mulheres e à paridade política entre homens e mulheres.

A midiatização vista na sua complexidade desafia-nos a ir além das questões de similitude pelas quais muitas vezes formam-se coletivos nas relações sociais estabelecidas em uma ambiência. Os coletivos são também marcados por tensões, disputas de pontos de vista, como percebemos principalmente no agrupamento "posicionamento político". Conforme lembra Verón (2004), não há causalidades no mundo dos discursos, havendo dissonâncias entre as instâncias da produção e do reconhecimento. Como postula Fausto Neto (2018), a circulação evidencia muito mais divergências que convergências.

Ao observar, descrever e analisar processos sociais por meio da Comunicação permite-nos, em diferentes escalas, compreender a sociedade e também transformá-la. Nesse contexto, há desafios de ordem teórica e metodológica, como a impossibilidade de analisar a totalidade dos discursos em 
uma situação comunicacional, mas apenas alguns fragmentos. Dessa maneira, sem almejar fórmulas ou manuais, mas com inquietações e observações acerca da comunicação em diversos fluxos, compartilhamos a busca de caminhos possíveis para compreender as complexidades constitutivas dos processos de circulação.

\section{Referências bibliográficas}

Barba, M. D. y Wentzel, M. (2016, abril 20). Discurso de Bolsonaro deixa ativistas 'estarrecidos' e leva OAB a pedir sua cassação. BBC Brasil. Recuperado de https://www.bbc.com/ portuguese/noticias/2016/04/160415_bolsonaro_ongs_oab_mdb

Braga, José Luiz. (2012). Circuitos versus Campos Sociais. En Mattos, M. Â., Janotti Jr., J. y Jacks, N. (Org.). Mediação e midiatização (pp. 29-52). Salvador: EDUFBA.

Braga, José Luiz. (2017). Circuitos de Comunicação. En Braga, J. L. et al. (Org.). Matrizes Interacionais: A Comunicação Constrói a Sociedade, vol.2 (pp. 43-64). Campina Grande: EDUEPB.

Braga, José Luiz. (2020). Polarização como estrutura da intolerância: uma questão comunicacional. En Heller, B., Cal, D. y Rosa, A. P. da (Org.). Midiatização (in)tolerância e reconhecimento (pp.19-35). Salvador: EDUFBA.

Brandes, U. (2001). A faster algorithm for betweenness centrality. The Journal of Mathematical Sociology, 25(2), 163-177. DOI: https://doi.org/10.1080/o022250X.2001.9990249

Degenne, A. y Vergès, P. (1973). Introduction à l'analyse de similitude. Revue Française de Sociologie , 14(4), 471. Recuperado de https://www.jstor.org/stable/3320247? origin=crossref

Falcão, M. \& Guerreiro, G. (2014, abril 9). Para rebater deputada, Bolsonaro diz que não a 'estupraria'. Folha de S. Paulo. Recuperado de http://www1.folha.uol.com.br/ poder/2014/12/1559815-para-rebater-deputada-bolsonaro-diz-que-nao-a-estupraria. shtml

Fausto Neto, Antônio. (2018). Mediação, midiatização: conceitos entre trajetórias, biografias e geografias. En Ferreira, J. et al. (Org.). Entre O Que Se Diz E O Que Se Pensa: Onde Está A Midiatização? (pp. 63-99). Santa Maria: FACOS / UFSM.

FENAJ. (2020, julho 7). Bolsonaro é denunciado na ONU por ataques contra mulheres jornalistas. Federação Nacional dos Jornalistas. Recuperado de https://fenaj.org.br/bolsonaro-e-denunciado-na-onu-por-ataques-contra-mulheres-jornalistas/

Fórum. (2017, abril 5). Bolsonaro: "Eu tenho 5 filhos. Foram 4 homens, a quinta eu dei uma fraquejada e veio uma mulher". Revista Fórum. Recuperado de https://revistaforum. com.br/noticias/bolsonaro-eu-tenho-5-filhos-foram-4-homens-a-quinta-eu-dei-uma-fraquejada-e-veio-uma-mulher-3/

Frigo, Diosana; Romero, Luan Moraes. (2021). \#EleNão: circulação de sentidos no período eleitoral em grupos de mulheres no Facebook. Anais de Artigos do Seminário Internacional de Pesquisas em Midiatização e Processos Sociais, [S.l.], v. 1, n. 4, abr. 2021. ISSN 2675-429o. Disponível em: <https://midiaticom.org/anais/index.php/seminario-midiatizacao-artigos/article/view/1332>. Acesso em: 17 dez. 2021.

Frigo, Diosana. (2018). Circulação de sentidos e a memória da ditadura civil-militar no acontecimento o "voto de Jair Bolsonaro" no impeachment de Dilma Rousseff. 2018. Dissertação (Mestrado em Comunicação Midiática) - Centro de Ciências Sociais e Humanas, 
Universidade Federal de Santa Maria, Santa Maria, RS.

Frigo, Diosana; Dalmolin, Aline e Borelli, Viviane. (2020). Acontecimento, discursos de ódio e intolerância: uma análise da circulação do voto de Jair Bolsonaro no impeachment de Dilma Rousseff. En Heller, B., Cal, D. y Rosa, A. P. da (Org.). Midiatização (in)tolerância e reconhecimento (pp. 37-60). Salvador: EDUFBA.

G1. (2020, julho 29). Bolsonaro veta projeto que previa prioridade a mulher chefe de família no pagamento do auxílio emergencial. G1. Recuperado de https://g1.globo.com/politica/ noticia/2020/o7/29/bolsonaro-veta-projeto-que-previa-prioridade-a-mulher-chefe-de-familia-no-pagamento-do-auxilio-emergencial.ghtml

ISTOÉ. (2020, agosto 11). Bolsonaro é alvo de ação por falas sobre mulheres. ISTOÉ. Recuperado de https://istoe.com.br/bolsonaro-e-alvo-de-acao-por-falas-sobre-mulheres/

Lebart, L., Salem, A. y Berry, L. (1998). Exploring Textual Data. [S.L.], Springer Netherlands.

Newman, M. E. J. \& Girvan, M. (2004). Finding and evaluating community structure in networks. Physical Review e, 69(2), 69-74. American Physical Society (APS). DOI: http:// dx.doi.org/10.1103/physreve.69.026113

ONU. (2020, setembro 24). Estudo conduzido pelo PNUD e pela ONU Mulheres sobre direitos políticos das mulheres coloca o Brasil em $9^{\circ}$ lugar entre 11 países da América Latina. ONU Mulheres Brasil. Recuperado de https://www.onumulheres.org.br/noticias/estudo-conduzido-pelo-pnud-e-pela-onu-mulheres-sobre-direitos-politicos-das-mulheres-coloca-o-brasil-em-9o-lugar-entre-11-paises-da-america-latina/

Romero, L. M. (2021). Série Vaza Jato: Análise do circuito comunicacional formado em torno das três primeiras reportagens. 2021. 102 f. Dissertação (Mestrado) - Programa de Pós-graduação em Comunicação, Universidade Federal de Santa Maria, Santa Maria.

Verón, E. (1997). Esquema para el análisis de la mediatización. Revista Diálogos de Comunicación, n. 48, Lima: Felafacs.

Verón, E. (2004). Fragmentos de um tecido. São Leopoldo: Editora Unisinos.

Van Dijck, J., Poell, T. \& De Waal, M. (2018). Platform society: public values in a connective world. Nova York: Oxford University Press. 